Proceedings

\title{
The Effect of Climate and Human Pressures on Functional Diversity and Species Richness Patterns of Amphibians, Reptiles and Mammals in Europe ${ }^{\dagger}$
}

\author{
Mariana A. Tsianou *, Maria Lazarina, Aristi Andrikou-Charitidou, Danai-Eleni Michailidou and \\ Athanasios S. Kallimanis
}

Citation: Tsianou, M.A.; Lazarina, M.; Andrikou-Charitidou, A.;

Michailidou, D.-E.; Kallimanis, A.S The Effect of Climate and Human Pressures on Functional Diversity and Species Richness Patterns of Amphibians, Reptiles and Mammals in Europe. Proceedings 2021, 68, $\mathrm{x}$. https://doi.org/10.3390/xxxxx

Academic Editor:

Published: date

Publisher's Note: MDPI stays neutral with regard to jurisdictional claims in published maps and institutional affiliations.

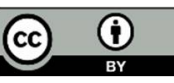

Copyright: (C) 2021 by the authors Submitted for possible open access publication under the terms and conditions of the Creative Commons Attribution (CC BY) license (http://creativecommons.org/licenses/by/4.0/).
1Department of Ecology, School of Biology, Aristotle University of Thessaloniki, GR-54124 Thessaloniki, Greece; mlazarin@bio.auth.gr (M.L.); andrikou@bio.auth.gr (A.A.-C.); dmichail@bio.auth.gr (D.-E.M.); kalliman@bio.auth.gr (A.S.K.)

* Correspondence: mtsianou@bio.auth.gr

+ Presented at the 1st International Electronic Conference on Biological Diversity, Ecology and Evolution, 1531 March 2021; Available online: https://bdee2021.sciforum.net/.

\begin{abstract}
The ongoing biodiversity crisis reinforces the urgency to unravel diversity patterns and the underlying processes shaping them. Although taxonomic diversity has been extensively studied and is considered the common currency, conserving simultaneously other facets of diversity such as functional diversity is critical to ensure ecosystem functioning and provision of ecosystem services. Here, we explored the effect of key climatic factors (temperature, precipitation temperature seasonality, precipitation seasonality) and factors reflecting human pressures (agricultural land, urban land, land-cover diversity, population density) on functional diversity (functional richness and Rao quadratic entropy) and species richness of amphibians (68 species), reptiles (105 species) and mammals (160 species) in Europe. We explored the relationship between different predictors and diversity metrics using Generalized Additive Mixed Model analysis, to capture non-linear relationships and to account for spatial autocorrelation. We found that at this broad spatial scale, climatic variables exerted a significant effect on functional diversity and species richness of all taxa. On the other hand, variables reflecting human pressures exerted a significant effect only on reptile and mammal diversity, and their explanatory power was lower compared to climatic variables. In most cases, functional richness and Rao quadratic entropy responded similarly to climate and human pressures. Concluding, climate is the most influential factor in shaping both functional diversity and species richness patterns of amphibians, reptiles and mammals in Europe. However, incorporating factors reflecting human pressures complementary to climate could be conducive to our understanding the drivers of functional diversity and richness patterns.
\end{abstract}

Keywords: taxonomic diversity; functional richness; Rao quadratic entropy; climatic variables; Generalized Additive Mixed Models; macroecological patterns; diversity drivers

\section{Introduction}

As different processes and multiple factors act simultaneously to shape the observed biodiversity patterns at different scales, much macroecological research aims to understand the underlying mechanisms shaping biodiversity patterns [1,2]. Till recently, the main representative of biodiversity to assess such questions was species diversity, and primariy species richness. Yet, analysing biodiversity patterns goes beyond species richness. For example, species' functional traits can define their distribution, persistence or colonization in a given environment [3]. Functional diversity, the species' functional traits within communities and ecosystems [4], is quantified by arranging species in a functional trait space according to their functional trait values [5]. This representation allows us to 
measure various aspects of functional diversity such as functional richness, i.e., the overall volume of trait space (niche) occupied by species in a community [6] or Rao quadratic entropy, i.e., the functional distance between all pairs of species within a community [5]. Functional diversity and its various aspects could be a suitable tool to improve our knowledge on how to unlock the role of environmental variation on biodiversity patterns and thus ecosystem functioning.

Climate and seasonality drive species' distribution [7] and functional diversity patterns [8-11]. Climatic factors affect biodiversity patterns via physiological limitations and functional traits (e.g., small-bodied ectotherm species achieve an optimum temperature more rapidly to cope with the low temperatures of northern latitudes) [12], and thus, drive functional diversity via environmental filtering. According to the environmental filtering effect, climate harshness and other abiotic factors potentially could act as a sieve toward circumscribing species' functional traits to be predominantly determined by environmental conditions [10]. The filtering effect predicts that climate harshness will decrease functional diversity provoking higher trait similarity between species [8-11]. On the other hand, environmental variability enables species with different ecological niches to co-exist in the same region, indicating that seasonality could act not only as a filter of species traits but also promote greater dissimilarity among co-occurring species [11,13]. As such, climate seasonality could increase functional diversity through higher dissimilarity of species traits [14] or decrease functional diversity through higher similarity of species traits [15].

Human pressures (like agriculture, urbanization or human population density) have a conducive role in explaining traits' geographical variation and functional diversity [1618]. Agricultural intensification may act as an environmental filter [19] on functional diversity patterns. However, there are counterexamples showing that urban and agricultural land changes influence community structuring and thus functional diversity by favoring species' specific adaptations to cope with the new environments [16]. Recent studies report that urbanization has substantial negative impacts on functional diversity and that highly urbanized communities show significant decreased functional diversity in contrast with the natural environments $[20,21]$. But still, understanding the contribution of human pressures on large scale patterns of functional diversity and their relative importance compared to other mechanisms such as climate remains fragmentary $[16,18,22]$. Furthermore, functional diversity patterns have generally been investigated to single taxonomic groups, despite the fact that different taxa may play similar and/or complementary ecological and functional roles $[16,23]$. Studies on comparative analyses of functional roles and functional diversity patterns of different taxonomic groups are scarce and focused primarily on local scales $[16,20]$, while the same question but for broad scale data is still in its infancy butsee [23].

Functional traits and functional diversity link biodiversity to the environment and ecosystem functioning. Therefore, examining how functional diversity changes with the environment is key to understanding the implications of climate and anthropogenic factors in ecosystem processes. Here, we examine the functional diversity patterns of three taxonomic groups (amphibians, reptiles and mammals) across Europe and explore the effect of climatic variables (temperature, precipitation, temperature seasonality and precipitation seasonality) and human pressures (agricultural and urban land area, land-cover diversity and human population density) on their functional diversity patterns. Amphibians, reptiles and mammals might either have similarities in key functional roles (e.g., amhibians-reptiles) or differ in ecological roles (mammals) but having a direct linking (e.g., one taxonomic group as a feeding resource for another). Given the scale and extent of our study we expect that climate will have a stronger influence on these patterns $[11,24]$ in contrast to the human pressures which mainly act at local scales butsee $[16,18,25]$. 


\section{Methods}

\subsection{Species Distribution Data}

We compiled distributional data for 68 amphibian species, 102 reptile species and 160 mammal species of Europe from two atlases, 'The Atlas of European amphibians and reptiles' [26] and 'The Atlas of European Mammals' [27]. Both atlases provide distributional presence/absence data on 2488 equal area grid cells of $50 \mathrm{~km} \times 50 \mathrm{~km}$ which were based on field surveys, published records and national atlases projected on the same coordinate reference system WGS84.

\subsection{Trait Data}

We compiled trait datasets for amphibians, reptiles and mammals of Europe using a number of available databases (published papers, books, electronic databases given upon request). The selection of traits was based on the completeness of the availability of species' trait data and on their previous use of them in quantifying amphibian, reptile and mammal functional diversity [14,22]. Our trait selection process resulted in the following nine functional traits: (a) body length (body mass for mammals), (b) clutch size (litter size for mammals), (c) age at sexual maturity, (d) reproductive period (only for amphibians and reptiles), (e) oviposition site (only for amphibians and reptiles), (f) activity time, (g) diet type, (h) foraging location and (i) mobility mode (only for amphibians and reptiles) ( $a-c$ traits were considered as numerical variables and $d-i$ traits as binary variables).

\subsection{Functional Diversity Indices}

Functional diversity of each grid cell was estimated by metrics previously evaluated for their relationship with species richness [28] and amongst them [29]: (a) functional richness: the convex hull volume occupied by the species of each grid cell and (b) functional Rao quadratic entropy measured as the distance between two randomly selected species within the grid cell. We applied a Gower distance matrix to capture both the numeric and the binary variables in our trait dataset and then performed Principal Coordinates Analysis (PCoA) to ordinate species along the major axes and arrange them in a multidimensional functional trait space. Metrics were calculated using "dbFD" function in the R package "FD" [30].

\subsection{Environmental Data}

We used four climatic variables retrieved by WorldClim climate database [31]: temperature, precipitation, temperature seasonality, precipitation seasonality and four variables related to human pressures: agricultural land area, urban land area, land-cover diversity and population density to investigate their relationship with functional richness and Rao quadratic entropy. Landscape data (agricultural land area, urban land area, landcover diversity) were provided by the land cover dataset CLC2000 [32] and human population density was obtained from HYDE Gridded Population version 3.1 [33]. The environmental data were reprojected and resampled to the same projection and resolution as the distribution data in QGIS version 2.10.0.

\subsection{Statistical Analysis}

We applied Generalized Additive Mixed Models (GAMMs) with the "gamm" function of the "mgcv" $\mathrm{R}$ package [34], predicting the functional diversity (functional richness and Rao quadratic entropy seperately) and species richness of amphibians, reptiles and mammals as a function of the climatic predictors and those related to human pressures. We used Poisson error distribution for species richness and Gaussian error distribution for functional diversity indices. To account for spatial autocorrelation, we included spatial correlation structure of coordinates (Gaussian distribution). All the predictors were modelled as smooth predictors with penalized thin plate regression splines $(\mathrm{k}=3)$. Prior to 
modelling, we checked for multicollinearity among variables, applying the variance inflation factor (VIF). Since all VIF values scored $<10$, we included all variables in the model. Total precipitation and precipitation seasonality were square-root transformed; landcover diversity, agricultural area extent and human population density were log10-transformed. Grid cells with less than 50\% land-cover were excluded from the analysis.

\section{Results \& Discussion}

We found similar functional richness patterns for amphibians and reptiles in Europe, with a clear latitudinal pattern (Figure 1), while mammal functional richness exhibited moderate to high values across all Europe (Figure 1). Here, we provide distribution maps only for functional richness of the three taxa (Figure 1) due to space restrictions. Crosstaxon relationships of the functional diversity indices revealed moderate associations between amphibians and reptiles (functional richness: $\mathrm{R}^{2}=0.24, p<0.001$, Rao quadratic entropy: $R^{2}=0.46, p<0.001$ ), and mammal functional diversity was weak related to amphibian (functional richness: $\mathrm{R}^{2}=0.01, p<0.001$, Rao quadratic entropy: $\mathrm{R}^{2}=0.05, p<0.001$ ) and reptile functional diversity (functional richness: $\mathrm{R}^{2}=0.07, p<0.001$, Rao quadratic entropy: $\mathrm{R}^{2}=0.14, p<0.001$ ).

Amphibians

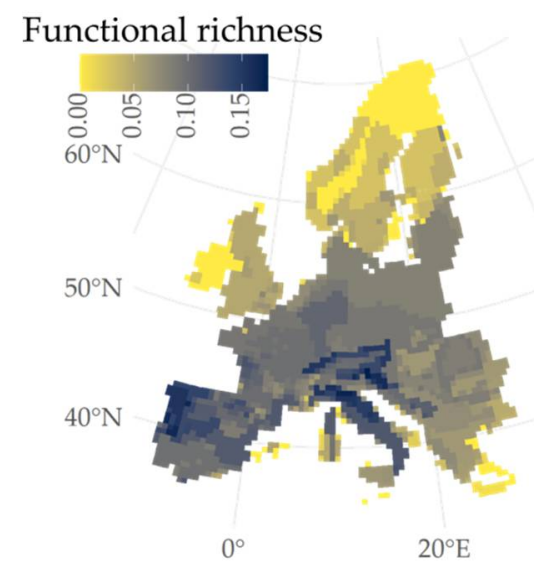

Reptiles

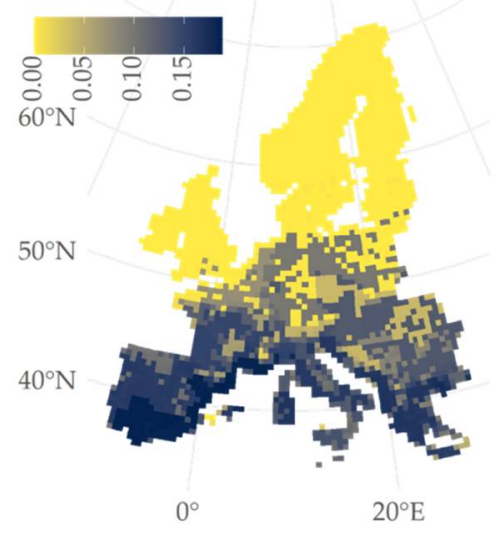

Mammals

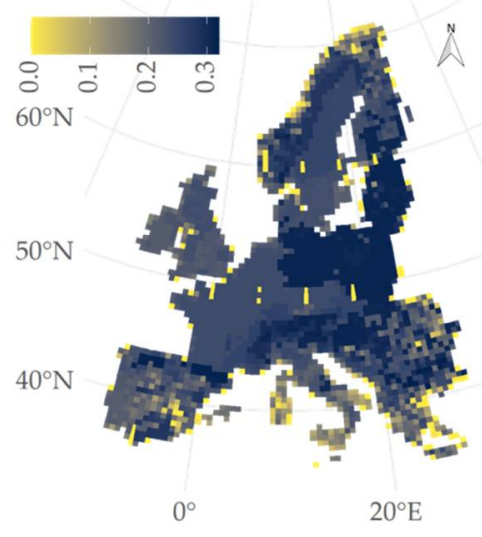

Figure 1. Functional richness distribution patterns of amphibians, reptiles and mammals of Europe $(50 \mathrm{~km} \times 50 \mathrm{~km}$ grid cell size).

Species and functional richness, and Rao quadratic entropy of all taxa showed strong significant relationships with climatic variables. Human pressures exerted a significant effect on Rao quadratic entropy of amphibian, reptile richness, and species and functional richness of mammals (Figure 2). Climate is considered more influential than landscape in explaining species richness [2,35] and functional diversity at broad spatial scales [11,24]. On the other hand, although landscape and human pressures related factors mainly act at local scales [18,20], we detected their imprint also at broader scales see also [35]. Amphibian and reptile richness and functional diversity increased significantly with increasing temperature, while for mammals the relationship with temperature was either unimodal or decreasing (Figure 2). Amphibians and reptiles are ectotherms with specific thermal ranges, thus specific adaptations are required to establish their survival in stressful environmental conditions. On the other hand, previous research indicate that mammal functional diversity accommodates higher species "packing" in areas with higher temperature leading to higher similarity of traits between species and thus decrease of functional diversity [14]. Precipitation reflecting water availability affects reproduction of ectotherm species, and its significance has been previously demonstrated for ectotherm richness [36] 
and functional diversity [22]. Here, reptile functional diversity increased with precipitation, while a unimodal relationship was observed in the case of amphibians and mammals.

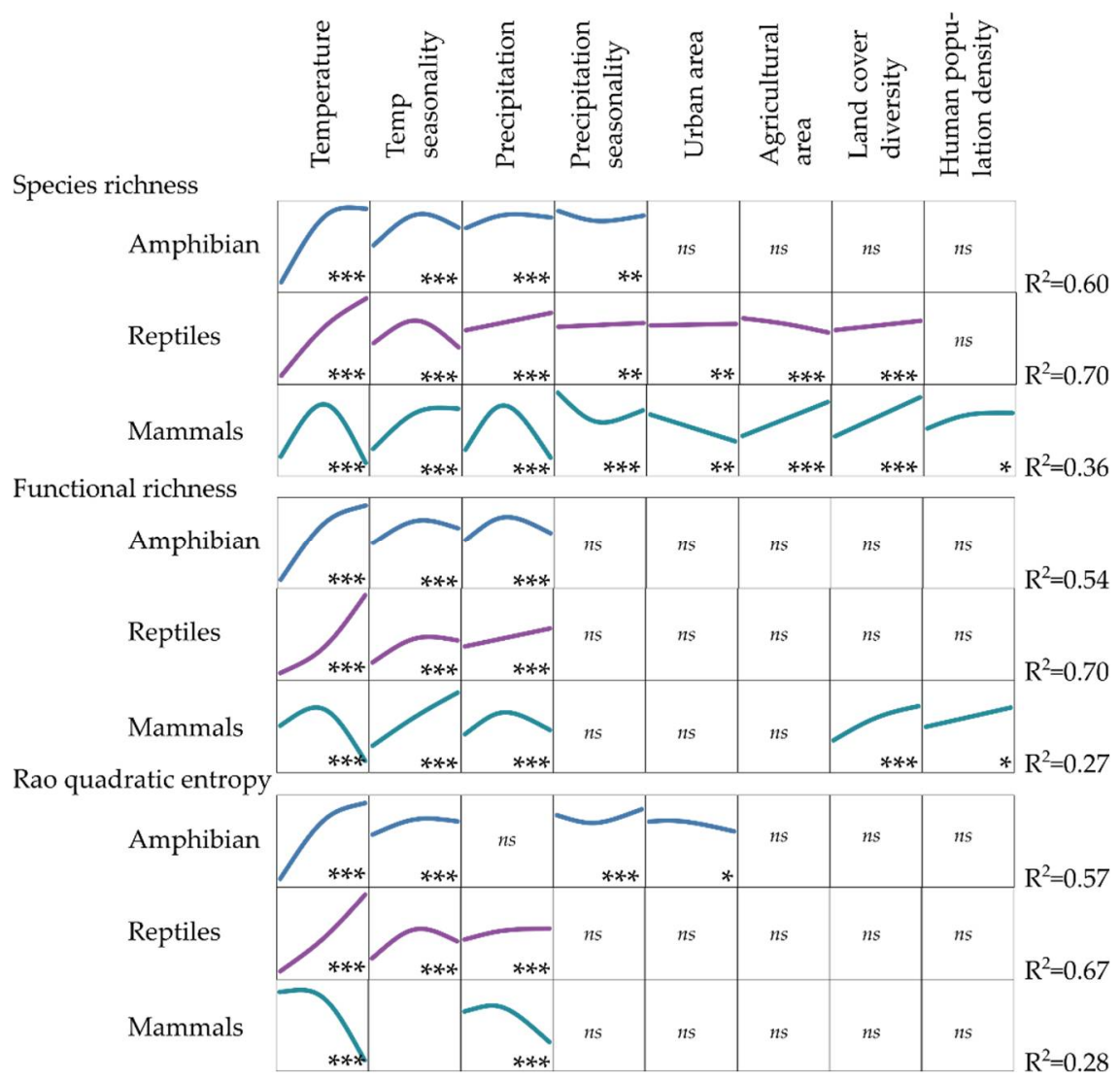

Figure 2. Summary plot showing the results of Generalized Additive Mixed Models predicting species richness, functional richness and Rao quadratic entropy of amphibian, reptiles and mammals of Europe as function of of climatic, land uses- and human pressures related variables.

There has been a lot of discussion about the key effect of seasonality on functional diversity patterns $[10,11,14,22]$. Seasonality performed either as a driver or filter for functional traits of amphibians, reptiles and mammals of Europe. Amphibian and mammal functional richness exhibited a significant unimodal relationship with temperature seasonality, and reptile showed an increasing relationship (Figure 2). Therefore, we demonstrate that seasonality drives broad-scale functional diversity following previous research $[10,11]$.

Our results suggest that variables related to human pressures have the potential to act as drivers or filters of the functional diversity patterns. For example, Rao quadratic entropy of amphibians decreases with increasing urban land area. This complies with recent research on avian functional diversity patterns and urbanization [21] and confirms that the expansion of urbanization might have negative impacts on functional diversity. A decreasing trend due to urbanization could be translated as an indication of functional homogenization within the amphibian communities emerging increasing similarity of community trait composition. On the other hand, mammal functional richness tended to increase with increasing land cover diversity, i.e., the higher habitat heterogeneity of a region, the higher niche diversity could support. Thus, we demonstrate that functional diversity increases in regions with high landscape heterogeneity.

We found that although amphibians, reptiles and mammals differ in their ecological roles, their responses to the various determinants was largely consistent implying that the 
taxa may share similarities in their responses. However, we used a variety of traits to calculate multi-trait functional diversity indices and trade-offs might spring between different traits, blurring the responses to environmental drivers. For instance, one trait largely filtered by an abiotic factor is not necessarily reflected to changes in other traits (even though this is way that species with dissimilar functional roles survive under harsh climatic conditions and seasonal environments) [11]. Hence, there is a need to consider the different aspects of functional diversity to assess distribution patterns along various gradients. Finally, climate, land uses and other human related factors influence species assemblages synergistically, rendering hard to decipher their individual effect on distribution patterns [25], but this might be related to scale analysis. Here, we found that some human-landscape factors significantly affected diversity patterns at broad spatial scales.

\section{Conclusions}

Our study highlighted the roles of climate and variables related to human pressures on shaping functional diversity of amphibians, reptiles and mammals of Europe. We found a strong effect of climate, with the role of human pressures being significant- albeit of lower impact. The effects of urban land area and human population density on functional diversity patterns reported here might have irreversible negative impacts on taxonomic groups such as amphibians which are the most endangered group of vertebrates, thus resulting in impaired provision of ecosystem services. Functional diversity consists a significant dimension of biodiversity which bridges ecosystem functioning and community responses to environmental change. To enhance our understanding on determinants and processes which govern functional diversity patterns is valuable for maintaining ecosystem resilience and stability.

Author Contributions: M.A.T., M.L. and A.S.K. conceived and designed the research; M.A.T. collected the data; M.L. and D.-E.M. performed the statistical analysis; M.A.T. and M.L. contributed to result interpretation and manuscript writing. All authors contributed to the final version of the manuscript. All authors have read and agreed to the published version of the manuscript.

Funding: Hellenic Foundation for Research and Innovation (H.F.R.I.) under the "First Call for H.F.R.I. Research Projects to support Faculty members and Researchers and the procurement of high-cost research equipment grant".

\section{Institutional Review Board Statement:}

\section{Informed Consent Statement:}

\section{Data Availability Statement:}

Acknowledgments: The research work was supported by the Hellenic Foundation for Research and Innovation (H.F.R.I.) under the "First Call for H.F.R.I. Research Projects to support Faculty members and Researchers and the procurement of high-cost research equipment grant" (Project Number: HFRI-FM17-2024 Mapping Functional Diversity Drivers, Impacts and Threats-MAPFUN). Results presented in this work have been produced using the Aristotle University of Thessaloniki (AUTh) High Performance Computing Infrastructure and Resources. The authors would like to acknowledge the support provided by the IT Center of the Aristotle University of Thessaloniki (AUTh) throughout the progress of this research work.

Conflicts of Interest: The authors declare no conflict of interest.

\section{References}

1. Gaston, K.J. Global patterns in biodiversity. Nature 2000, 405, 220-227.

2. Field, R.; Hawkins, B.A.; Cornell, H.V.; Currie, D.J; Diniz-Filho, J.A.F.; Guégan, J.F.; Kaufman, D.M.; Kerr, J.T.; Mittelbach, G.G.; Oberdorff, T. Spatial species-richness gradients across scales: A meta-analysis. J. Biogeogr. 2009, 36, 132-147.

3. Allen, A.P.; Brown, J.H.; Gillooly, J.F. Global biodiversity, biochemical kinetics, and the energetic-equivalence rule. Science 2002, 297, 1545-1548.

4. Petchey, O.L.; Gaston, K.J. Functional diversity: Back to basics and looking forward. Ecol. Lett. 2006, 9, 741-758. 
5. Villéger, S.; Mason, N.W.; Mouillot, D. New multidimensional functional diversity indices for a multifaceted framework in functional ecology. Ecology 2008, 89, 2290-2301.

6. Mason, N.W.; Mouillot, D.; Lee, W.G.; Wilson, J.B. Functional richness, functional evenness and functional divergence: The primary components of functional diversity. Oikos 2005, 111, 112-118.

7. Willig, M.R.; Kaufman, D.M.; Stevens, R.D. Latitudinal gradients of biodiversity: Pattern, process, scale, and synthesis. Annu. Rev. Ecol. Evol. Syst. 2003, 34, 273-309.

8. Mason, N.W.; Irz, P.; Lanoiselée, C.; Mouillot, D.; Argillier, C. Evidence that niche specialization explains species-energy relationships in lake fish communities. J. Anim. Ecol. 2008, 77, 285-296.

9. Schleuter, D.; Daufresne, M.; Veslot, J.; Mason, N.W.; Lanoiselée, C.; Brosse, S.; Beauchard, O.; Argillier, C. Geographic isolation and climate govern the functional diversity of native fish communities in European drainage basins. Glob. Ecol. Biogeogr. 2012, 21, 1083-1095.

10. Swenson, N.G.; Enquist, B.J.; Pither, J.; Kerkhoff, A.J.; Boyle, B.; Weiser, M.D.; Elser, J.J.; Fagan, W.F.; Forero-Montaña, J.; Fyllas, N. The biogeography and filtering of woody plant functional diversity in North and South America. Glob. Ecol. Biogeogr. 2012, 21, 798-808.

11. Shiono, T.; Kusumoto, B.; Maeshiro, R.; Fujii, S.J.; Götzenberger, L.; de Bello, F.; Kubota, Y. Climatic drivers of trait assembly in woody plants in Japan. J. Biogeogr. 2015, 42, 1176-1186.

12. Rodrigues, J.F.M.; Olalla-Tárraga, M.Á.; Iverson, J.B.; Diniz-Filho, J.A.F. Temperature is the main correlate of the global biogeography of turtle body size. Glob. Ecol. Biogeogr. 2018, 27, 429-438.

13. Canavero, A.; Arim, M.; Brazeiro, A. Geographic variations of seasonality and coexistence in communities: The role of diversity and climate. Austral. Ecol. 2009, 34, 741-750.

14. Safi, K.; Cianciaruso, M.V.; Loyola, R.D.; Brito, D.; Armour-Marshall, K.; Diniz-Filho, J.A.F. Understanding global patterns of mammalian functional and phylogenetic diversity. Philos. Trans. R. Soc. B Biol. Sci. 2011, 366, 2536-2544.

15. Brown, J.S.; Kotler, B.P.; Porter, W.P. How foraging allometries and resource dynamics could explain Bergmann's rule and the body-size diet relationship in mammals. Oikos 2017, 126, 126.

16. Concepción, E.D.; Götzenberger, L.; Nobis, M.P.; de Bello, F.; Obrist, M.K.; Moretti, M. Contrasting trait assembly patterns in plant and bird communities along environmental and human-induced land-use gradients. Ecography 2017, 40, 753-763.

17. Rapacciuolo, G.; Marin, J.; Costa, G.C.; Helmus, M.R.; Behm, J.E.; Brooks, T.M.; Hedges, S.B.; Radeloff, V.C.; Young, B.E.; Graham, C.H. The signature of human pressure history on the biogeography of body mass in tetrapods. Glob. Ecol. Biogeogr. 2017, 26, 1022-1034.

18. Sams, M.; Lai, H.; Bonser, S.; Vesk, P.; Kooyman, R.; Metcalfe, D.; Morgan, J.; Mayfield, M. Landscape context explains changes in the functional diversity of regenerating forests better than climate or species richness. Glob. Ecol. Biogeogr. 2017, 26, 11651176.

19. Flynn, D.F.; Gogol-Prokurat, M.; Nogeire, T.; Molinari, N.; Richers, B.T.; Lin, B.B.; Simpson, N.; Mayfield, M.M.; DeClerck, F. Loss of functional diversity under land use intensification across multiple taxa. Ecol. Lett. 2009, 12, $22-33$.

20. Concepción, E.D.; Moretti, M.; Altermatt, F.; Nobis, M.P.; Obrist, M.K. Impacts of urbanisation on biodiversity: The role of species mobility, degree of specialisation and spatial scale. Oikos 2015, 124, 1571-1582.

21. Sol, D.; Trisos, C.; Múrria, C.; Jeliazkov, A.; González-Lagos, C.; Pigot, A.L.; Ricotta, C.; Swan, C.M.; Tobias, J.A.; Pavoine, S. The worldwide impact of urbanisation on avian functional diversity. Ecol. Lett. 2020, 23, 962-972.

22. Tsianou, M.A.; Kallimanis, A.S. Geographical patterns and environmental drivers of functional diversity and trait space of amphibians of Europe. Ecol. Res. 2020, 35, 123-138.

23. Cooke, R.S.; Bates, A.E.; Eigenbrod, F. Global trade-offs of functional redundancy and functional dispersion for birds and mammals. Glob. Ecol. Biogeogr. 2019, 28, 484-495.

24. Bello, F.D.; Lavorel, S.; Lavergne, S.; Albert, C.H.; Boulangeat, I.; Mazel, F.; Thuiller, W. Hierarchical effects of environmental filters on the functional structure of plant communities: A case study in the French Alps. Ecography 2013, 36, $393-402$.

25. Barnagaud, J.Y.; Geniez, P.; Cheylan, M.; Crochet, P.A. Climate overrides the effects of land use on the functional composition and diversity of Mediterranean reptile assemblages. Divers. Distrib. 2021, 27, 50-64.

26. Sillero, N.; Campos, J.; Bonardi, A.; Corti, C.; Creemers, R.; Crochet, P.-A.; Isailović, J.C.; Denoël, M.; Ficetola, G.F.; Gonçalves, J. Updated distribution and biogeography of amphibians and reptiles of Europe. Amphib. Reptil. 2014, 35, 1-31.

27. Mitchell-Jones, A.J.; Amori, G.; Bogdanowicz, W.; Krystufek, B.; Reijnders, P.; Spitzenberger, F.; Stubbe, M.; Thissen, J.; Vohralik, V.; Zima, J. The atlas of European Mammals; Academic Press: London, UK, 1999; Volume 3.

28. Mouchet, M.A.; Villéger, S.; Mason, N.W.; Mouillot, D. Functional diversity measures: An overview of their redundancy and their ability to discriminate community assembly rules. Funct. Ecol. 2010, 24, 867-876.

29. Tsianou, M.A.; Kallimanis, A.S. Different species traits produce diverse spatial functional diversity patterns of amphibians. Biodivers. Conserv. 2016, 25, 117-132.

30. Laliberté, E.; Legendre, P.; Shipley, B.; Laliberté, M.E. Package 'FD'. Meas. Funct. Divers. Mult. Trait. Other Tools Funct. Ecol. 2014.

31. Hijmans, R.J.; Cameron, S.E.; Parra, J.L.; Jones, P.G.; Jarvis, A. Very high resolution interpolated climate surfaces for global land areas. Int. J. Climatol. J. R. Meteorol. Soc. 2005, 25, 1965-1978.

32. Heymann, Y. CORINE Land Cover: Technical Guide; Office for Official Publ. of the Europ. Communities: 1994.

33. Goldewijk, K.K.; Beusen, A.; Van Drecht, G.; De Vos, M. The HYDE 3.1 spatially explicit database of human-induced global land-use change over the past 12,000 years. Glob. Ecol. Biogeogr. 2011, 20, 73-86. 
34. Wood, S.; Wood, M.S. Package 'mgcv'. R Package Version 2015, 1, 29.

35. Xu, C.; Huang, Z.Y.; Chi, T.; Chen, B.J.; Zhang, M.; Liu, M. Can local landscape attributes explain species richness patterns at macroecological scales? Glob. Ecol. Biogeogr. 2014, 23, 436-445.

36. Rodríguez, M.Á.; Belmontes, J.A.; Hawkins, B.A. Energy, water and large-scale patterns of reptile and amphibian species richness in Europe. Acta Oecologica 2005, 28, 65-70. 